\title{
Analysis on Accountability System of Public Welfare Foundation in Our Country
}

\author{
Donglin Yang \\ Wuhan University of Science and Technology \\ Wuhan, Hubei, China
}

\begin{abstract}
Since the reform and opening up, economy in China flourishes gradually, GDP grows rapidly and social polarization is also expanding sharply. Therefore, the idea of "supporting the poor and relieving vulnerable groups" has sprung up since ancient times. At present, the government has been unable to meet all requirements of social welfare, so their attitude towards charitable activities becomes more positive and they encourage it. Public welfare foundations aiming at developing philanthropy spread all over China like mushrooms after rain. But with exposure of accounting scandal of increasingly number of public welfare foundations, the sense of trust from the public for public welfare foundations reduces gradually as well. Aiming at problems existing in development of foundations, this article puts forward the solutionaccountability. There are many forms of accountability. The following part mainly discusses external accountability with contributor as subject identity and internal accountability of establishing internal audit department, looking forward to better development of public welfare foundation in our country.
\end{abstract}

\section{Keywords—public benefit; foundation; accountability}

\section{ORIGIN AND DEVELOPMENT OF PUBLIC WELFARE FOUNDATION}

In 2004, the State Council published the Regulations on Funds, clearly dividing foundations into public-raising foundation and non-public foundation and allowing the foundation in China to enter the rapid development stage after the registration of private foundations. According to report of 2011 annual inspection work conference of foundation held by Non-governmental Organization Administration Bureau of Ministry of Civil Affairs, by the end of 2011, the quantity of foundations in our country reached up to 2,500. Compared with that of 2005 , the average annual growth rate reaches up to $20 \%$. The growth trend of quantity of foundations in China is great. At present, the total assets of foundations in our country reach 60.42 billion yuan. The general income of annual donation is 33.7 billion yuan. The total annual public welfare expenditure is 25.6 billion yuan. Foundations in China enter the rapid development stage.

However, so far, most of them are government-run foundations, which are products under specified conditions of China. Obstacles met by commonweal organizations launched by private person are mainly regulations of "dual enrollment" and vague tax policy. However, there is quite broad zone between strict prohibition and perfect legitimacy. It can be called "grey zone", with Chinese characteristics. In recent years, various kinds of public welfare organizations and activities spring up exuberantly in this zone. Except for personal efforts, the awareness of entrepreneurs also raises. The word "enterprise citizen" and the concept of "enterprise social responsibility" enjoy popular support. All of these make positive contributions to education, poverty alleviation, environmental protection, and aid for women, children and the disabled as well as academic activities.

\section{REASONS TO CONSTRUCT ACCOUNTABILITY SYSTEM OF PUBLIC WELFARE FOUNDATION}

Although public welfare foundations develop rapidly, many problems that are worthy of attention expose in this process. The following reasons make the accountability implemented for public welfare foundation particularly important.

\section{A. External Laws and Regulations Are Imperfect.}

Charitable cause and charitable foundations always face the problem that whether the finance is transparent. The lack of laws and regulations is important influence factor. Regulations on Funds, Measures for the Information Disclosure of Foundations, non-government institution of "China Foundation Center" and Charity Transparency List introduced by Chinese version of Forbes magazine do not disclose specific requirements. As early as around the year of 2000, the case that the accountant of National Natural Foundation embezzled public funds of 200 million yuan happened. Non-transparent and nonstandard financial system gives the criminals readily exploitable loopholes to embezzle public funds. Besides, the public welfare funds is embezzled, borrowed to operate highrisk industries, which do not conform to its public welfare purpose. However, because of imperfect systems and lack of competent authorities to timely supervise, they can only remedy through subsequent investigation. Therefore, from the level of supervision, it is imperative to make laws to supervise finance to promote transparent development of foundations. Charitable organizations in China have gone through all kinds of hardships and the credibility vanishes. If events such as the "event of Guo Meimei" appear again for several times, maybe these charitable organizations can only rely on financial fund to survive in the end. 


\section{B. Internal Management Ability Is Low}

Except for problems in institutional aspect, the development of foundations in our country faces problems of internal management. It shows in the low ability of foundations in raising funds, nonstandard fund use and low efficiency in use. In terms of ability of foundations to preserve or increase the value, the income from investment of Chinese Red Cross Foundation in 2012 was zero. Half of the income comes from donation of about 117 million yuan. The rest of it comes from government subsidies of 88.57 million yuan, accounting for $37.85 \%$. By contrast, the ability of overseas famous foundations to preserve or increase the value is stronger. For example, the income of Bill and Melinda Gates Foundation in 2011 was 3,410,000 U.S. dollars, with donation income of 2,783,000 U.S. dollars and investment income of 622,000 U.S. dollars. The investment income accounts for $18.27 \%$ of general income of foundations. Because of appropriation and support from national finance, some government-run public welfare foundations in our country make no attempt to make progress. Under this circumstance, it is necessary to construct accountability system as soon as possible to publish and criticize foundations of "nonfeasance" and their behaviors in wasting social resources.

\section{Legal Consciousness of Industry Insiders Is Faint}

The new Fund Law has canceled the article that "foundation shall not operate and management enterprise" but stipulated the article that "legal representative of foundation shall not hold the post of legal representative of other organizations meanwhile, to prevent internal interest transportation". Here, we have to return to problem mentioned above about ineffective supervision of supervisors. Although rules expressly stipulate it, at present, many responsible people of foundations hold a concurrent post of legal representative in enterprises. It is even a relatively common phenomenon. This time Mr. Zhou exposes and blames that Li Yapeng serves as the founder of Smile Angel Foundation as well as legal representative of cultural company. The Civil Servant Law forbids on-the-job civil servants to hold any post in any enterprise. We have reason to believe that most civil servants at the grass-roots level clearly know about it. However, the phenomenon of obvious violation of laws and regulations exist in interior of industry of foundation. Most people think "I am not afraid because I do not commit a blunder". It is no exaggeration to say that some responsible people of foundation do not realize it is a problem. It reflects the public pay little attention to responsible people of charitable foundations. The so-called internal and external supervision does not work.

Generally speaking, the corruption phenomenon existing in foundation of our country is serious. The transparency of financial information disclosure is insufficient. The credibility of brand image of foundation is seriously inadequate. Supervisory mechanism is not implemented. The phenomenon of chaotic internal governance is relatively serious. These further influence the future development of public welfare foundation in China. It becomes very urgent topic for discussion about how to improve governance of public welfare foundation in China. The accountability for public welfare foundation becomes very important.

\section{WAYS TO CONSTRUCT ACCOUNTABILITY SYSTEM OF PUBLIC WELFARE FOUNDATION}

\section{A. Principal Part of Accountability System}

On constructing accountability mechanism of public welfare charitable foundation, take relevant principal parts as main breakthrough to analyze. They are mainly economic donators. Because "clear act of authorization (not political power but economic power) exists between foundation and donators", donators carry out economic empowerment for foundation, the accountability on foundations is the right of donators. In pale of law, the relation between right and obligation is unity of opposites. It requires foundations to fulfill relevant obligations and undertake related responsibilities.

1) Government serves as donator: From the perspective that government serves as donator, the funds of appropriation come from tax revenue paid by citizens and enterprises. But the government must be responsible for citizens and enterprises, so it must appear as principal part of accountability. The accountability of government for foundation must rise to advanced level of law. The government shall make efforts to perfect legislation of foundation and realize effective supervision on the level of government by law. The sound operation and development of foundations in China, realizing optimal configuration of its capital resources and letting limited resources create the biggest social benefit have close relationship with establishing and improving effective government supervision system. For government, the most effective supervision is to use legal means to restrain operation of foundation. Only sound laws and regulations can provide institutional guarantee for development of foundations in China and provide legal basis for government to enforce the law. For example, Law of the People's Republic of China on Donations for Public Welfare (1990), Contract Law of People's Republic of China (1999) restrain donation of property source related to foundations in China. In 2004, the State Council issued Regulations on Funds. However, so far, our nation does not issue unified, specific and comprehensive Law of Foundation. In addition, comprehensive Law of Foundation of China shall restrict behaviors of foundations. It shall regulate behaviors that are allowed to exist, protected, limited and prohibited strictly as well as the consequence and punishment in contravention of law. These problems are in urgent need of solution.

New Law of Foundation shall also state foundations must set up information disclosure system to realize sharing and flow of information. At present, it cannot be realized according to current situation of foundations in our country. According to statistical data analysis results from Ministry of Civil Affairs in China, it shows that many foundations do not publish basic information, even without website and phone call, let alone exposure of fund use and disclosure of financial affairs. Unified legislation helps to realize accountability in advance and then improve sense of trust of the public for public welfare undertakings in China; the promulgation and implementation of laws also provide reference basis for government to realize 
effective supervision and effectively prevent the government from using improper administrative act.

2) Enterprises serve as donators: From the perspective of enterprises, devoting to charitable cause to properly donate some properties can enjoy some national preferential tax policy, realize the goal to increase returns, improve recognition degree of the public for corporate image and strengthen popularity and transfer positive energy. Under this circumstance, the number of enterprises supporting charitable foundations will increase gradually. Therefore, as one of the major principal parts of fund investment, the accountability of enterprises for foundations is necessary, in order to supervise that the foundations use materials donated by enterprises to truly benefit people in need of help. Firstly, in general case, donations from enterprises are mainly capitals and products with large quantity and amount of money, so foundations shall publish the source and use as well as subsidized objects to realize information flow. Only in this way can they get recognition and understanding from the public; Secondly, enterprises shall also require foundations to publish basic information of subsidized objects, in order to supervise whether the foundations select beneficiaries fairly and openly; Thirdly, enterprises need to implement performance examination of public benefit activities carried out by related charitable organizations by using capitals and products provided by enterprises. It is not an easy thing to carry out performance examination of foundations. Expert Deng Guosheng advocates evaluating the performance from the following aspects in "APC evaluation framework" raised by him: "(1) Evaluate appropriateness of projects. Can the project involved be regarded as preferential project in development of local community? Does it conform to purpose of the organization? (2) Evaluate efficiency of projects. Including cost benefit of projects involved, whether the project save time in the process of implementation and the promotion situation of project experience in local place and other areas; (3) Evaluate effect of project. It involves "two degrees (the degree that the project activity adheres to the original plan and the realization degree of purpose), four changes (change of knowledge of beneficiaries, change of living conditions, change of lifestyle and behavior as well as change of spiritual outlook)"; (4) Evaluate social influence of projects. It involves evaluations on employment, gender and development, ecological environment, poverty elimination and influence of ethnic relationship; (5) Evaluate continuity of projects. It includes whether the management system is perfect, responsibility of administrative staff, the risk of project and follow-up management of project; (6) Evaluate degree of satisfaction of beneficiaries. It involves service attitude of beneficiaries toward staff or volunteers, service content, capital arrangement, time selection of project implementation, degree of satisfaction for results of project. From the level of actual operation, the accountability of government for public welfare foundation is carried out from system and macroscopic perspective, but it will inevitably cause undesirable interference of the government on it to some extent.

3) Citizens serve as donators: The contributions made by citizens to public welfare foundation are basically reflected in personal donation. From the quantity of input, compared with government and enterprises, citizens' ability in donation is low, so its influence on foundations is not a patch on the former two. Although citizens as donators have rights to carry out accountability on foundations, because personal ability is weak, it is difficult to realize effective accountability. The way of accountability carried out by people devoting to public welfare foundation is to pay close attention to feedback of beneficiaries and take it as the basis of accountability. If they find charitable foundations do not fulfill the commitment at all or not completely meet commitment, they can expose with the help of modern media or complain to department in charge of the business. It is undeniable that without the help of a third party, it is impossible for citizens to carry out accountability of decisions of charitable foundations, transparency of finance and performance.

4) Nation: From the perspective of nation, the reason for accountability of foundations is obvious - foundations do not fulfill the promise. From the perspective of the whole charitable cause, if the self-discipline of industry is insufficient, even with the strongest external supervision, it also needs them to strengthen and improve.

"Self-discipline of public welfare foundation in China means public welfare foundations center on regulations, perfect system of rules and regulations of the organization, construct operation mechanism of mutual restriction to guide and restrain internal behaviors, realize self-organization, selfmanagement and ensure sound development." Self-discipline has diversified ways. The primary task is to improve internal rules and regulations. It is also the priority among priorities to cultivate uncorrupted and efficient members of foundation. Although public welfare foundations in China are governmentrun, most of them do not have executive power and ways to make money, so they can survive only with self-discipline. Charitable foundations can realize long-term development through improving self-management skills and operation level as well as public credibility.

\section{PATtERnS OF ACCOUNTABILITy SySteM: Procedure, PERFORMANCE AND RESULT}

\section{A. Accountability of Procedure}

Collection and processing of data is the most important. It shall base on given procedures. The accountability of procedure has two elements: The first is to require relevant project manager to provide accurate and complete financial information; the second is to require the manager to supervise and report the management process to ensure that it conforms to purpose of foundations.

Accountability of procedure requires supervision and report in the whole management process to ensure the plan conforms to the anticipated requirements. For general commercial institutions, it often refers to profit, reflecting by 
indicators such as quantity of sale or dividend. But for foundations, it represents that whether it can effectively achieve the expected goal and whether it can effectively use resources. Besides, it is different from general commercial institutions on information expression. It is the core idea and very important for public welfare foundations to explain service structure achieved by using resources, whether it reaches expected mission.

\section{B. Accountability of Performance}

In short, the accountability of performance can be divided into two types: the first type is narrow or procedural, such as financial statement. The second type is non-financial and has relationship with efficiency, such as reasonable use of resources, efficiency of income and expenditure.

\section{Accountability of Results}

The accountability has relationship with results of public benefit activities and operational objectives and methods of institutions. In reality, the quantization of it is very difficult to realize. Firstly, the goal of public welfare foundations is extensive and long-term. It is hard to use several indicators to completely measure the results, so it can only start with another perspective to measure intensity, process and result of input. In public welfare foundations, improvement represents that the project has achieved certain goal, equivalent to the situation that general commercial institutions make profit. However, the results are always out of control. It is impossible to measure whether the indicator is non-financial. Therefore, different requirements exist inevitably, without unified measurement standard. It is very necessary to set up internal audit department.

\section{INTERNAL AUDIT}

In recent years, more and more public welfare foundations develop internal audit, which proves to be an effective tool. Nowadays, the credibility is disappearing gradually. The development is widely accepted by public institutions and private enterprises.

Internal audit must be independent of executive agency and has rights to determine audit scope and time, which must gain the favor of management layer. Employees responsible for auditing need to have professional knowledge and objective attitude towards auditing, ensure confidentiality of data in the process of internal audit and reject interference of personnel from any department and objectively report the facts. The audit conclusion must be clear. All factors can be evaluated. The audit procedures are divided into four types.

- The first is to collect relative information, formal or informal, oral or written, but the evidence may be insufficient from time to time.

- The second is that the final audit results must be confirmed by the outside world. Let the third party participate in the audit and express opinion in written form.

- The third is to observe actual operation or process and evaluate performance according to this. The advantage is that it can provide the most reliable evidences at that time. The disadvantage is that the effectiveness of data is only suitable for specified time.

- The fourth is to patrol on the spot and inspect records, documents or tangible assets. But it may appear the problems that the actual holder is unknown, existing certain errors.

\section{CONCLUSION}

On the whole, enterprises and individuals take an active part in construction of charitable and public service. It shows irreversible trend produced by objective requirements of the society and rich willingness to do good deeds in society. Although the public welfare foundation in China at present is very immature, generally speaking, favorable factors exceed negative factors by far. The beginning of the 21 st century coincides with new stage of public welfare undertakings in China. Even though there is still a long way for China to build the civil society with real self-discipline expected by westerners at present, when internal system and external legal environment are mature, the establishment of public welfare foundations of high level operation can be expected soon.

\section{REFERENCES}

[1] Deng Guosheng. Discussion on Accountability Mechanism of Nonprofit Organization [J], Chinese Public Administration, 2003, (3).

[2] Ge Daoshun. Analysis on Development of Foundations in China, Beijing: Social Sciences Academic Press, 2009 edition

[3] [America] Adler. A Guide to the Law of Charities in the United States, Beijing: China Social Sciences Publishing House, 2002 edition

[4] Xiao Meijuan. NGO Marketing, Collection and Accountability [M], Social Sciences Academic Press, 2005. 